\title{
DESIGN CRITERIA AND PROCEDURES FOR ARCHAEOLOGICAL SHELTERS: TOWARDS FLEXIBILITY THANKS TO ALGORITHMIC MODELLING
}

\author{
L. SBROGIÓ ${ }^{1 *}$, A. BASSO ${ }^{2}$, P. BORIN ${ }^{2}$, M.R. VALLUZZI ${ }^{1}$ AND A. GIORDANO ${ }^{2}$ \\ ${ }^{1}$ Department of Cultural Heritage (DBC) \\ Università degli Studi di Padova \\ piazza Capitaniato 7, 35139 Padova, Italy \\ e-mail: luca.sbrogio@unipd.it, mariarosa.valluzzi@unipd.it (*corresponding author) \\ ${ }^{2}$ Department of Civil, Environmental and Architectural Engineering, DICEA \\ Università degli Studi di Padova \\ Via Marzolo 9, 35131 Padova, Italy \\ e-mail: andrea.basso.1@studenti.unipd.it,paolo.borin@unipd.it, andrea.giordano@unipd.it
}

Keywords: Archaeological shelter, Algorithmic modelling, structural optimization, Flexible design

\begin{abstract}
Many examples of archaeological shelters can be found over sites and a wide range of literature illustrates their features. However, it seems that only a few have passed through a proper assessment phase of their effectiveness and compatibility to the archaeological remains. which is mainly due to proper detailing of the building solution in respect of general conservation criteria. Furthermore, in some cases, shelters have proven to worsen environmental conditions that they are supposed to protect. In this paper design criteria for archaeological shelters are proposed, in respect of the three main themes recognized as crucial: general architectural quality, conservation effectiveness, structural and functional detailing. To deal with the wide range of cases where such criteria must be applied, an innovative tool providing the desired flexibility in the design procedure is taken into consideration. Algorithmic modelling in Grasshopper environment, a plugin for Rhinoceros $3 D$ software, offers the required features thanks to a linear workflow, where the general characteristics of the structure as far as its structural details can be implemented. Every element is represented by a set of parameters in the plugin rather than a single object in the 'parent' modelling tool, thus allowing easy change to the design. Other plugins provide additional tools for specific tasks, such as finite element analysis, safety verifications and structural optimization. The paper presents the methodology for the implementation of the entire workflow and the preliminary assessment of its results, from the structural and architectural point of view, showing good adaptability to several possible design choices (position of pillars, truss number, roof pitch, etc.). Structural optimization is also executed. The future implementation of environmental parameters (e.g. daylight, ventilation, temperature), as an additional set of restraints, will complete the framework on which a final assessment will take place.
\end{abstract}




\section{INTRODUCTION}

The sheltering of archaeological sites has recently been considered more a consolidated practice than the correct response to a clearly stated problem [1]. In fact, shelters, open on the sides, are perceived as less demanding in terms of design and visually less intrusive in archaeological contexts than enclosures. Conversely, enclosures, which are 'permanent' structures completely confined by the means of a roof and walls, are completely designed and, as they encapsulate the vestiges, they substantially alter the perception of the ruins (Fig. 1). Shelters are specifically used for extensive archaeological sites where they cover limited portions of them, like a single house or a few rooms with fragile finishings such as mosaics or paintings. Enclosures are of their most effective with punctual and isolated remains [2].

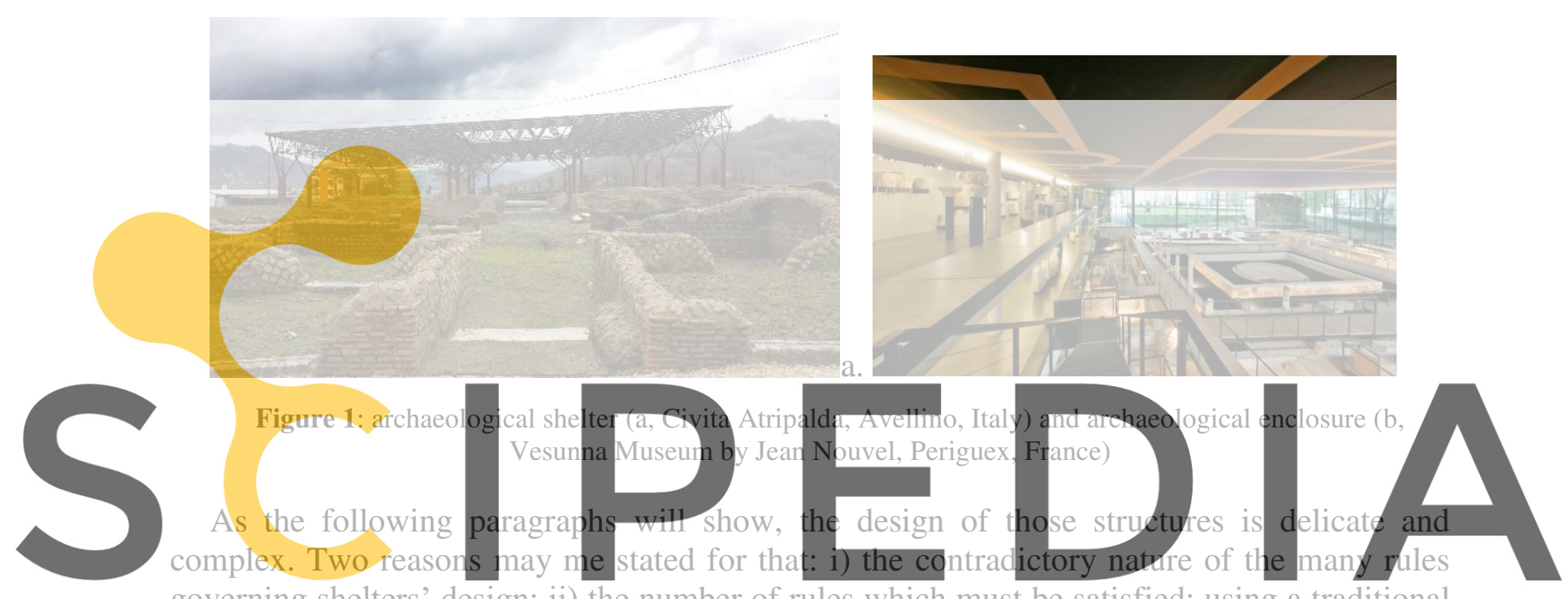

governing shelters' design; ii) the number of rules which must be satisfied: using a traditional

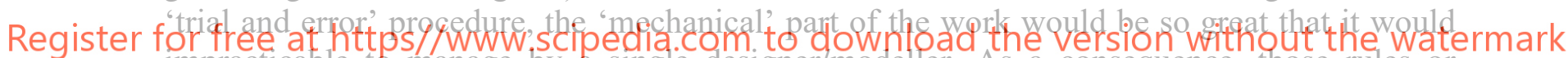
impracticable to manage by a single designer/modeller. As a consequence, those rules or

'criteria' should enter a procedure where someone else, say a computer, creates the shape by combining the values that the rules may assume. To that end, the designer should transform the modelling procedure, that is the steps he makes into a modelling software to obtain a specific form, and even the engineering part of the process, that is the structural calculations and verifications, into an algorithm which the computer may follow. The rules become the input variables of the algorithm, but, since many vary within a range, they are better defined as 'parameters'. The computer may then repeat again and again the algorithm in order to find the best solution, the optimum; which is a compromise between the most important criteria.

The paper presents a brief insight $(\$ 2)$ on the reasons of in situ archaeological conservations, the problems that this choice creates, and the criteria that may be used for shelters' design, from an architectural and a structural point of view.

Those criteria are transformed into the input parameters of an algorithm $(\S 3)$, which, for the sake of simplicity, defines a simple structure made of a flat grid of trusses supported by four pillars. Notwithstanding, many other architectural shapes may be defined, such as bidirectional frames, space frames and gridshells (Fig. 2; [3]). On the resulting prototype an optimization analysis, in order to find the combination between the structural shapes and the number of 
structural elements is executed (§ 4.2). Finally, each optimized prototype has been calculated and verified for gravity and progressively imposed loads $(\S 4.3)$.
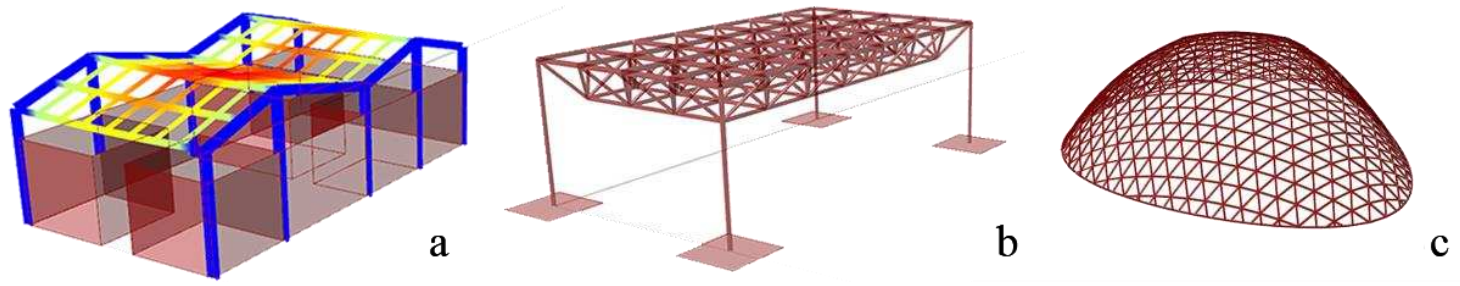

Figure 2: Examples of architectural shapes which may be defined through algorithmic modelling [3].

\section{ON SITE CONSERVATION AND DISPLAY OF ARCHAEOLOGICAL SITES}

The sheltering or enclosing of archaeological sites has become a common practice since the late 1980s, when the act of moving artefacts and decorative materials into museums from the places where they were found was considered as alteration of the perception of both, the objects and the architectural fragments left on site $[4,5]$. In fact, the former lost the environment which they were designed for, the latter were stripped of its characteristic elements. In situ conservation is therefore a powerful means to convey and thus preserve the memories of a place. The visitors' experience of the findings in the actual context of their discovery and of the architecture in its surrounding is an added value which no museum display technique could

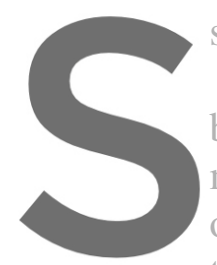
substitute $[4,5,6,7]$

However, preserving building or objects or to more traditional museu on their surface, that wh in situ archaeological
ools, imply a mach grea
$\mathrm{m}$ conservation. In fact,
hich is also the most ex materials, may
ater effort than
most values in
posed to variati be they gith
that which ma
cultural herit that may be attenuated only through conservation in controlled climatic conditions [8, 9].

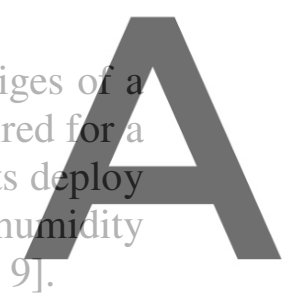

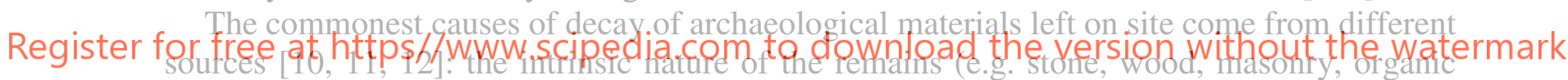
materials, etc.); anthropogenic (e.g. unwise handling of objects; vandalism; war conflict etc.); biological (e.g. small animals; vegetation); environmental (e.g. precipitations, temperature, humidity, light and invisible energetic radiation such as ultraviolet and infrared); chemical (e.g. pollution).

In addition, too often shelters and also enclosures have proved responsible for a negative impact on the ancient materials from several points of view. Such situations stem from unfavourable microclimatic conditions determined by the shelter or a premature deterioration of a shelter's structure and/or equipment $[1,13,14]$. The inadequacy of management and development plans on/for the site is another critical factor, which may depend either on the lack of economic resources needed to run them or on the overexposure of the site to contemporary human activities (generally tourism) $[15,16]$.

Notwithstanding, shelters and enclosures are potentially the best option for preserving archaeological materials since they belong to the field of preventive and corrective measures of conservation, that is they do not touch the fabric of the vestiges directly but work on their 'boundary conditions' $[2,4,10,17]$ while keeping the materials in their original place. In practice however, it seems that these interventions respond more often to either an immediate 
psychological need to 'see a roof over the ruins' or to the taste and interpretation of the designer $[2,12]$. Therefore, they are either the result of an almost non-existent design procedure or a biased one, where typically more importance is given to formal aspects than conservation. The abundant literature on the whole subject is of little help, since each scholar suggests different criteria or puts emphasis on certain aspects according to his/her own sensibility [18].

In the following, an excerpt of the main criteria will be enough to show the complexity of the subject.

\subsection{Decision making in shelter construction}

First of all, one has to decide whether a certain archaeological site will be left exposed after its excavation and documentation. The minimum criteria to support this decision are [19]: a) the importance of the archaeological materials; b) the potentiality to communicate the meaning and inform the public about the site; c) the diversity and the attractiveness of the site; d) the accuracy of the available archaeological documentation; e) the associative potential with similar monuments; f) a correct assessment of the site's values. Anyway, the reduction to a 'standard' procedure is impossible; for this reason, the choices relating to the archaeological sites are considered primarily ethical, rather than scientific [20].

Some help may come from looking at the extent of the remains, whether they are ruins and vestiges, where the former have lost their original unity and are now reduced to some walls and/or a pavement, while the latter preserve an echo of the original building. As a result, the former would best be in archaeological documentation, the tatter may be recomposed and reconfigured by a shelter [2]. Al\$o, sholtering, and thus altering, have acquired a proper dignit place, would be unjust fragile to be left exposed and at the same time by itself, may be completed by the shelter [22].

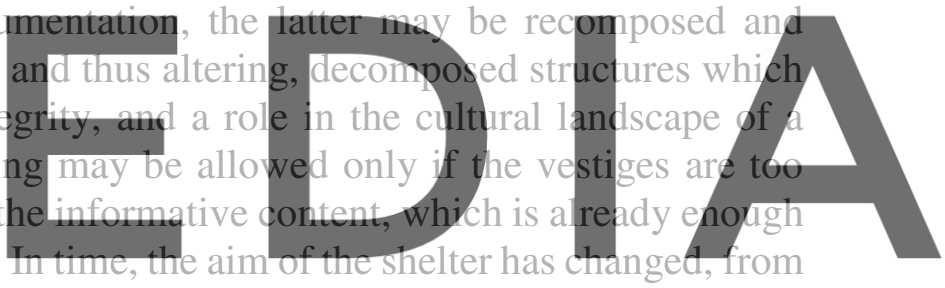
the museum [23] to the conservation of the fabric [12] and the transmission of values [5]. The

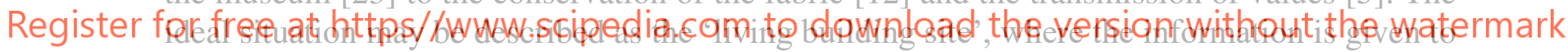

the public as it is extracted from the ground or it is preserved and the public returns the archacologists with moral and economic support. That is, the archacological site must play an active role in contemporary society $[5,6,15,16]$.

\subsection{Design criteria: general aspects}

Since the physical survival of archaeological materials is the main aim of every action taken on any archaeological site, the shelter should reduce and prevent in the long run its degradation, since arresting it would be impossible and conceptually wrong [12].

To this end, some authors express criteria and rules for design [24] while others [12] give indications for assessing the effectiveness of archaeological sheltering which may be translated in rules for design. Since a summary 'manual' many are the sources: i) theoretical approaches to restoration; ii) practical prescriptions for the conservation of objects and artefacts (see e.g $[11,25])$; iii) indications for in situ conservation of mosaics or adobe structures, which are the most fragile.

Three main themes may be recognized: general architectural quality, conservation effectiveness, quality and nature of structural and functional detailing. Researches in 
conservation $[7,10,12,26]$ detail the following criteria:

- $\quad$ General restoration: respect for authenticity; recognisability of interventions taken; reversibility; minimum intervention; the visitor's ability to understand the ruins;

Conservation: modification of microclimatic conditions; protection from external climatic agents; flexibility and expandability; natural illumination and ventilation; control of the vegetation (shadows, added humidity, leaves obstructing drainage system, roots); efficient drainage system; control of the greenhouse effect; control of direct illumination of archaeological materials; lateral confinement; lateral overhang;

- $\quad$ Formal and architectural: intrusiveness in the archaeological context; distinguishability from the remains; flexibility and expandability; natural illumination; height; lateral confinement; transparency; number and placement of bearing structure; quality of architectural details;

- $\quad$ Structural: easy conception and easier installation; simpler structural solutions make it easier to find spare parts and to execute maintenance; flexibility and expandability; foundations and footings; type;

Economic and management: the cost of the structural system and of its installation since they determine reversibility as the willingness to substitute the shelter if it proves inefficacious; the costs of maintenance; ease of maintenance; the cost for a/c and other equipment to keep the indoor climate constant; the long-term availability of financial and human resources to maintain the shelter and to nurture the archaeological site;

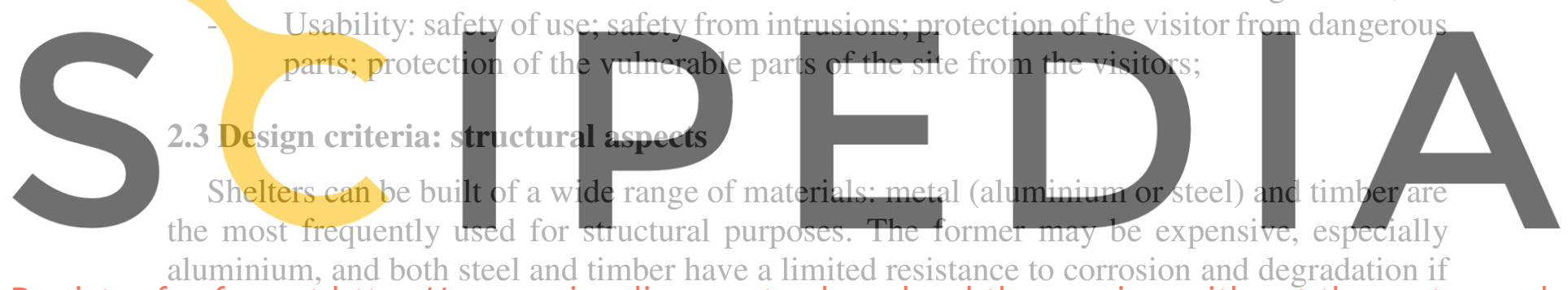

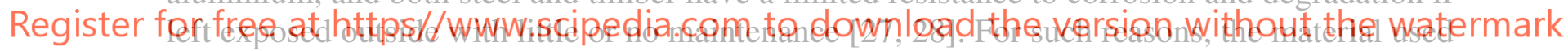

in the present proposal are the glass fiber reinforced polymers (GFPR) in the shape of pultruded structural sections [27]. Even though more expensive and rather complicated to be calculated, GFRP is i) almost an $80 \%$ lighter than steel; ii) corrosion resistant; iii) designable according to the needs [28].

Since long spans and minimum vertical supports are required, the commonest structural solutions for the covering structures are trusses, space frames, cable-supported structures and, more recently, long-span glued laminated timber beams; however, something that requires a limited number of vertical supports in the middle. The roof sheathing materials may be corrugated steel sheets, clay tiles, polycarbonate or glass panes; lateral confinement is generally provided by timber louvers, masonry walls, expanded metal sheets. As a general rule foundations are supposed to be outside the perimeter of the site but they may also be internal, provided that they do not interfere with the ancient structures, that is they fall along the ancient walls or in places that lack archaeological records [12]. Lightweight and small structures require small foundations and therefore they are more appreciated. 


\section{ALGORITHMIC MODELLING TOOLS}

In a normal 3D modelling process in a computer aided programme, the user has a limited access to the tree of modifiers which he/she adds to the primary objects in the modelling canvas of the software. In contrast, in parametric modelling the user translates the entire sequence of direct manipulations on the primary objects into encoded operations on the parameters and the variables which described the objects [29]. The story of modifications is collected by a Direct Acyclic Graph (DAG) which is a 'code' expressed graphically by the means of boxes ('components'), corresponding to the objects or their modifiers, and cables, which express the relation between the boxes [30]. DAGs allow a linear workflow but not loops. The algorithm works as an 'assembly instruction' which allows the user to focus on the process rather than the product, where inputs streams from the left of the input to the right of the output. Each minimal change in the parameters on the left corresponds to a different output on the right.

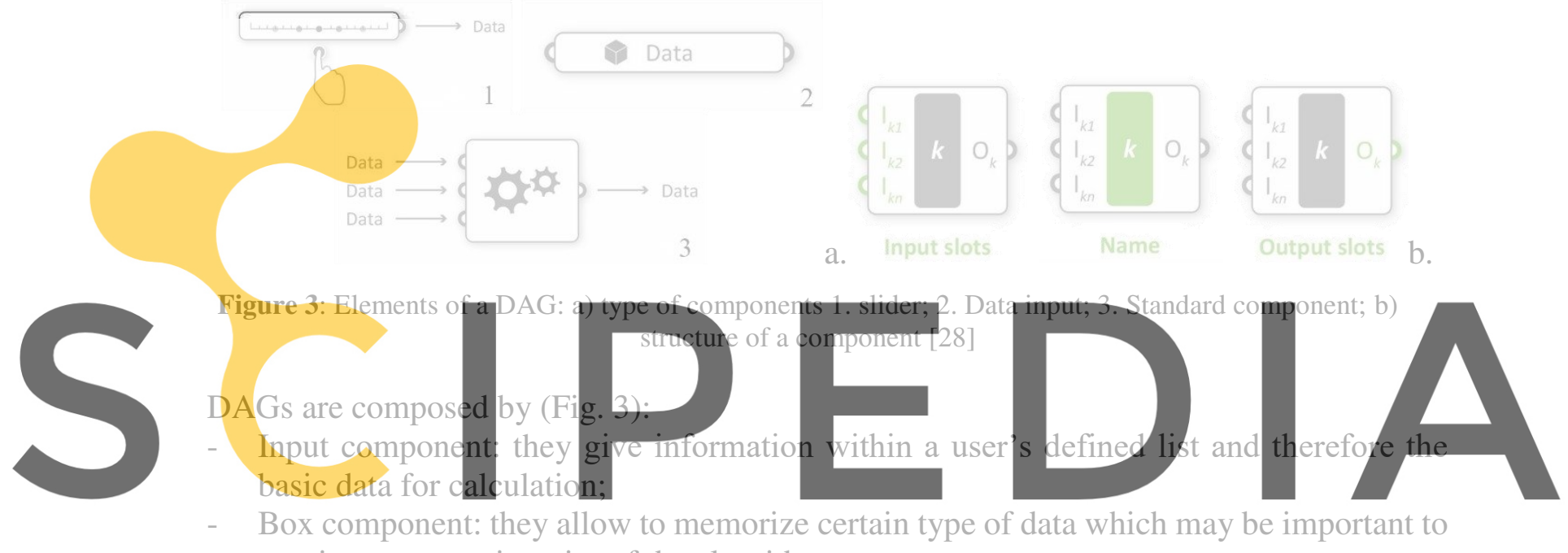

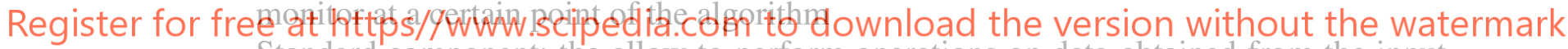
Standard component: the allow to perform operations on data obtained from the input, representing the minimum step of the overall procedure. They yield a single output as a result of multiple input.

Complex operations may be obtained by combining and clustering single components; the starting value may be a) assigned manually, selecting the value from a drop-down menu; b) obtained by selecting it from and object in the canvas; c) assigned by a cabled connection. Input and output may have different formats (e.g. enter points and then exit segments).

Variations on the parameters may be applied by the user, acting on the input components, or may automatically explored by the computer once an optimization analysis is run. To do so the designer must define an 'objective function' on which one or more variables may have at least a partial impact on it and then the computer performs the combinations in search for the one that best satisfies the function. The rules used to perform the combinations follow the schemes which govern the generation among populations and therefore are known as genetic algorithms [29]. Single or multi parameter optimization analysis is possible according to the piece of software used [31, 32, 33]. 


\section{DESIGN OF THE SHELTER}

The parameters are defined as a model's components, with precise features and function within a shelter's structure but whose specification may vary according to the site's characteristics and therefore they are not fixed once for all but may vary to the user's needs. As a result, they are input data - and that is the reason why they appear at the beginning of the algorithm - but they depend on the reasoning already presented.

\subsection{Parametric components}

The structural parts of the roof and the corresponding logical parts of the algorithm are [3]:

- Pillars: segments obtained by the vertical extrusion (each one independent from the others) of four base points selected by the user. Then those segments are divided in two by a middle point where side panels hang (Fig. 1a);

- Roof: the quadrilateral shape (however sloped) defined by the four base points is subdivided into the local $u$ and $v$ directions creating the trusses' grid at the lower chord. The points obtained at the intersections are then projected on a plane which may be not parallel to the one already defined, since the top chords may have an inclination different from the bottom ones. Then the base lines in the two directions and in the two planes are subdivided and then linked by segments to define the trusses; their number depends on a slider which grades the spacing between the elements (Fig. 1b);

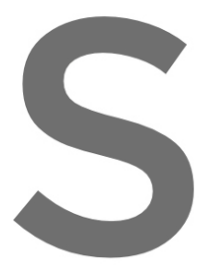
Overhangs: they are defined by two points which are projected for the desired distance from the upper extremity of the pillars
the length between two points on the san
spacing used in the quadrilateral of the
Side panels: their extremal nodes are
pillars and the overhang. Then, the

\section{pillars and the overnang, Then, the resulting re}
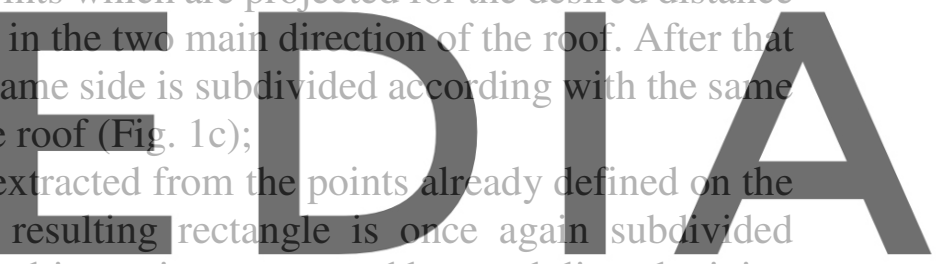

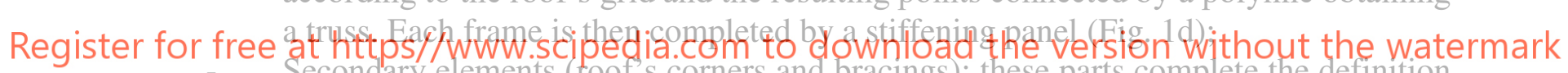

secondary elements (roof's corners and bracings): these parts complete the definition

of the overhangs at its corners and the introduction of additional bracing elements to

stiffen the edges of the roof (Fig. 1e, f).

Since a minimal shelter is made of four pillars, one roof, four overhangs and the corresponding corners and four side panels, similar elements have been grouped together to assign properties (e.g. structural shapes) which are shared within the group. However, this solution is also a matter of commodity when it comes to visualization or if a part/group is not needed (e.g. the side panels).

Each part is not fixed once for all but it has some dynamic features (or parameters) such as its dimensions or the number of elements it includes on in which it is subdivided which are determined by the user simply trough the mean of a slider in the algorithm's routine (Table 1). A change in any parameter affects the whole structure. 
Table 1: A shelter's logical-structural parts and corresponding parametric factors

\begin{tabular}{cc}
\hline Part (input) & Parameters \\
\hline Pillars & Height \\
& Position in plan \\
& Material \\
\hline Roof & External slope \\
& Internal slope \\
& Subdivision in $u, v$ directions \\
& Material \\
\hline Overhang & Dimension \\
& Material \\
\hline Side panels & Height \\
& Distance from the pillars \\
& Material \\
\hline Secondary elements & Dimension \\
& Number of bracing elements \\
& Material
\end{tabular}
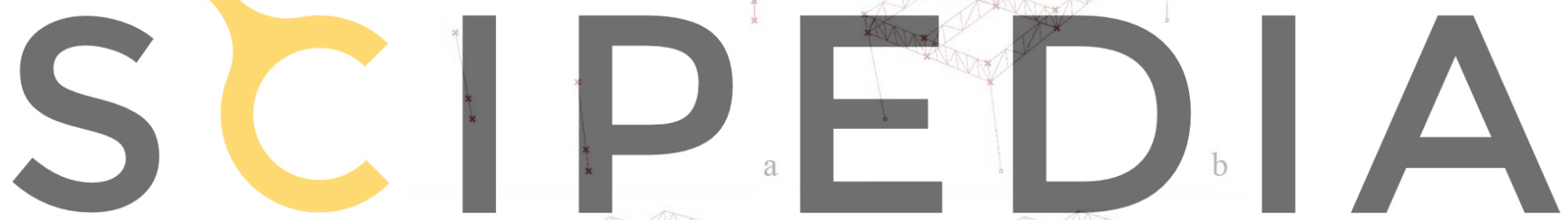

Register for free at https//www.scipedia.com to download the version without the watermark
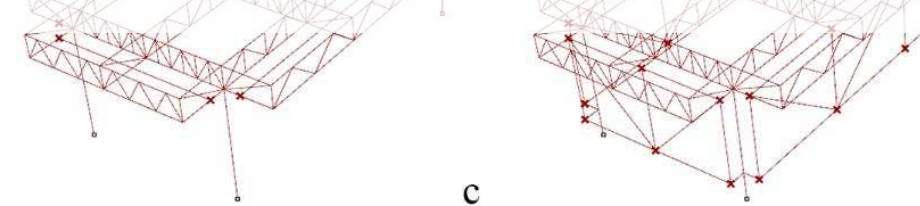

d

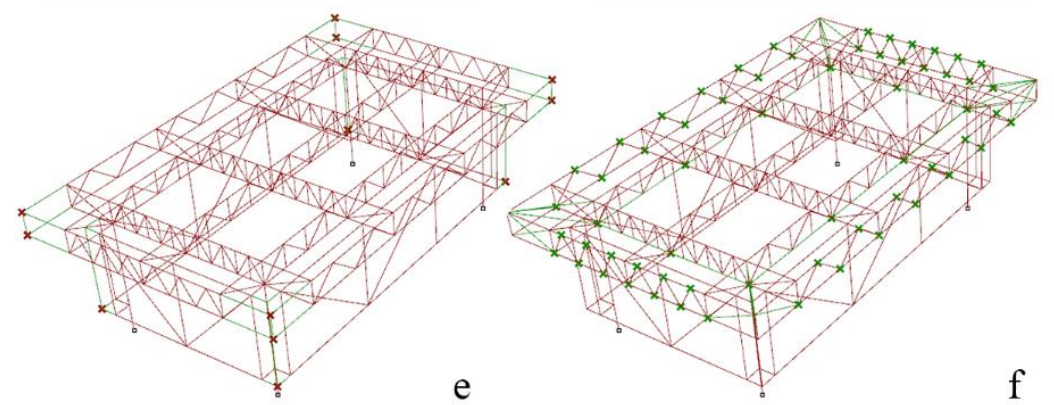

Figure 4: Structural parts of the shelter: a) pillars; b) roof (grid of trusses); c) overhang; d) side panels (only the frame is shown); e) corners; f) bracing stiffening elements [3]. 


\subsection{Finite element analysis and optimization}

Structural analysis is possible thanks to a plugin for Grasshopper, Karamba 3D [34], whose potential stays in the real-time structural calculation of $t$ the elements in the parametric model. To that end, however, the geometric model has to be converted into an analytical model, which bears the minimal characteristics to be calculated, through special components. Extremal nodes are then constrained according to the needs; like other FEA tools, in Karamba, internal nodes are considered continuous otherwise specified. Other components of the DAG allow to label each element, in order to distinguish groups and assign the structural shapes (extracted from libraries or used-defined) and the materials (default materials are steel, concrete, timber and aluminium but user-defined properties are also allowed). Finally, one must define the loads: gravity for the self-weight, and the different types of imposed ones. The solution consists mainly of the maximum nodal displacement and the system's deformation energy, but thanks to other components one can manage the model and obtain the forces acting on structural elements, the nodal reactions, nodal displacements etc. (Fig. 2).
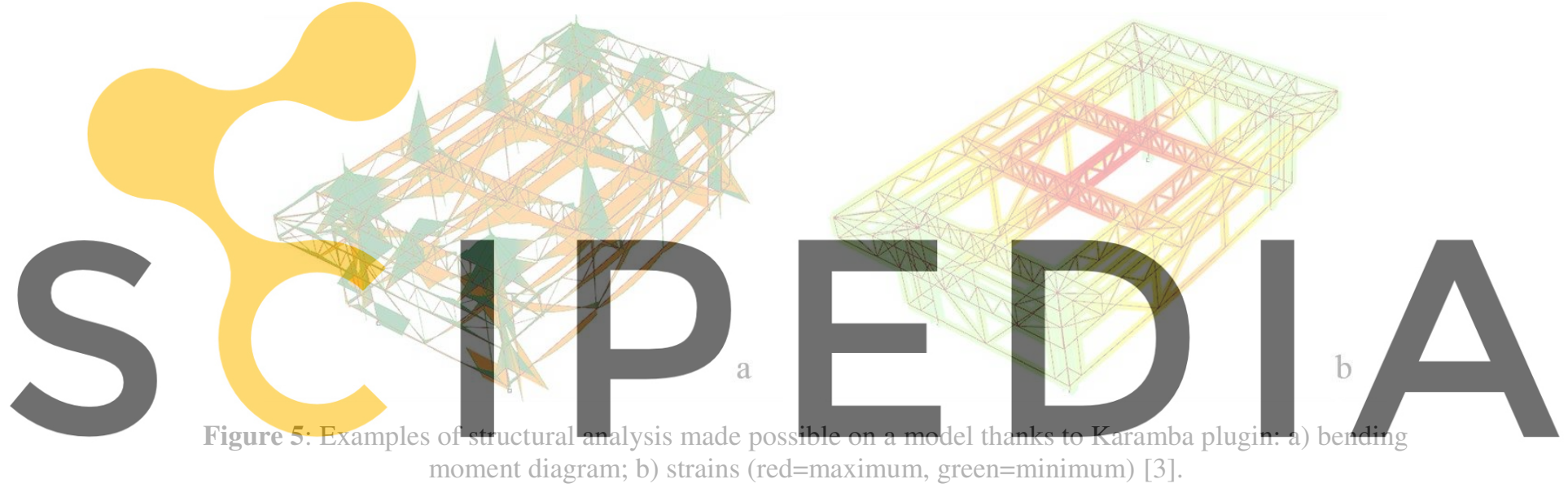

Register for free at https//www.scipedia.com to download the version without the watermark

The search of the best combination of parameters, say the number of trusses in the two directions of the grid, the number of bays within each truss and the structural shapes to be used have been committed to the software. In this case a function relating the mass and the deformation has been defined as suggested by $[32,33]$ adding a multiplier to scale the effects. Since more than one parameters are involved in the optimization procedure, Octopus plugin has been used.

\subsection{Prototypes: structural analysis and structural verifications}

For the structural analysis six prototypes have been defined, three of them squared and the other three rectangular with an aspect ratio 1:2, from a minimum of $3 \times 3 \mathrm{~m}$ to a maximum of $5 \times 10 \mathrm{~m}$. Other common features are: $3 \mathrm{~m}$ intrados height, $0,7 \mathrm{~m}$ trusses structural depth, 1,5 m overhang, flat roof (Fig. 3). The structural elements are made of GFRP pultruded shapes, whose orthotropic properties [27, 28] have firstly converted into an equivalent homogenous material [28] and then applied to the model. Previously to structural analysis, each structure has been optimized in Octopus. The applied loads, apart from gravity, which is kept constant, are 
incremented at steps of $0,5 \mathrm{kN} / \mathrm{m} 2$ until the structural limits at the serviceability limit state (SLS) are reached. calculated according to the formulations proposed in consensual laws [35].

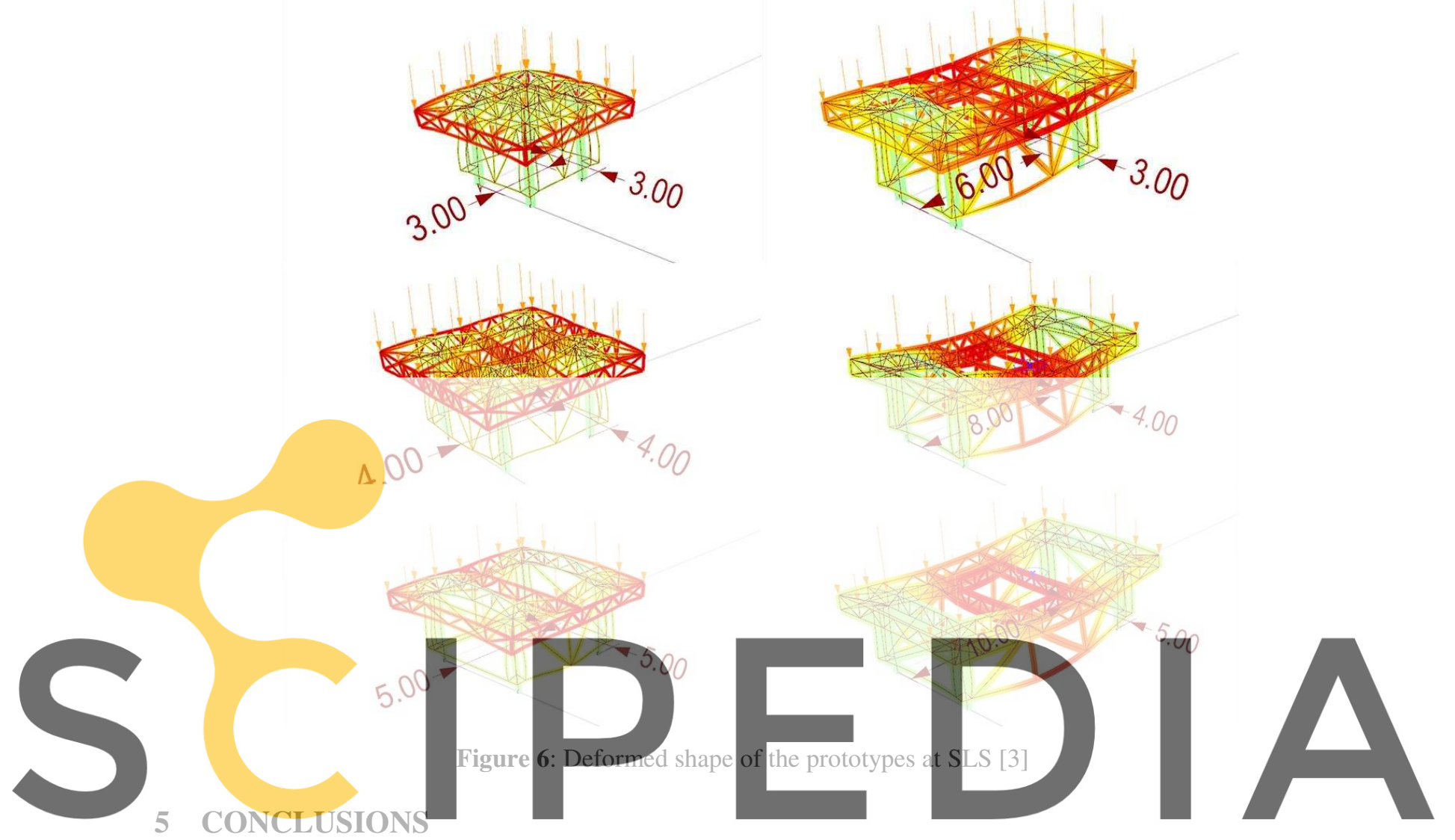

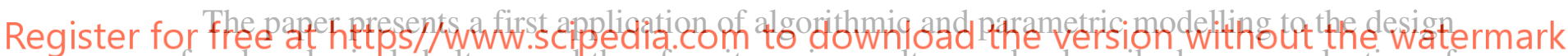 of archaeological shelters, and therefore its main results may be described as an evaluation of \\ the possibilities and the potential opened by this approach.}

In an ordinary design process, the validation of a proposal in respect to the structural and architectural criteria is done at the end, but, in the case of multiple-constrained tasks, such as the design of an archaeological shelter, this approach is ineffective. As a result, the criteria must become the input variables and the constraints of a process which may respond automatically to their variations, allowing the required flexibility. In Rhinoceros 3D modelling environment, the plugin Grasshopper for algorithmic design offers the needed tools thanks to the visual programming, which is a simplified code writing through the means of objects in a canvas.

In Grasshopper any engineering design process may be translated into an algorithm: the paper presents the logical structure of the procedure to obtain a flat grid of trusses supported by four pillars. The elements (pillars, trusses, overhang, side panels) are chosen and defined according to the criteria while their precise features are parametrically variable and not set once for all. As a result, other sub-plugins (Octopus, Galapagos), which exploit genetic algorithms, can be used to execute an optimization analysis, that is to explore the combinations and permutations of the input parameters in order to find the best solution. In this paper, the 
parameters are the number of subdivisions in horizontal structural elements (trusses, overhang) and the structural sections, once the structural heights and the position of the supports are fixed.

The optimization tools work on numerical data, which, in this case, are the internal forces and the deformations of the structure. These data are given by another plugin, Karamba 3D, which executes the structural analysis. The algorithmic modelling has shown its potential also in this case, since, basing on the result of Karamba, a piece of software purposely written assesses the safety of the structure according to the codes.

Thanks to these tools, six real-scale prototypes have been created, optimized and then calculated and assessed within the Grasshopper workflow. Their structural behaviour ath serviceability and ultimate limit states resulted satisfactory for a normal use in an archaeological context even though many improvements are possible both in the details and in the overall functioning.

Further research is also required to add the climatic and energetic criteria to the structuralarchitectural ones, to control their impact on the design process and one the optimized shape.

\section{REFERENCES}

[1] Aslan, Z., Court, S., Teutonico, J.M., Thompson, J. (Eds.) Protective shelters for archaeological sites. Los Angeles, (2018).

[2] Di Muzio, A. Rovine protette. Conservazione e presentazione delle testimonianze archeologiche. Firenze, (2013).

[3] Basso, A. Progettazione di sistemi a configurazione variabile per coperture di siti archeologici. Padova (2018).

[4] Ruggieri Tricoli, M. C. and Sposito C. I siti archeologici: dalla definizione del valore alla protezione della materia. Palermo, (2004).

[5] Avrami, E., Mason R. and De La Torre, M. (Eds.) Values and Heritage Conservation. Los Angeles, (2010).

[6] Agnew, N. and Brigland, J. (Eds). Of the Past, for the Future: Integrating Archaeology and Conservation. Los Angeles, (2006).

[7] Amendolea, B. (Ed.). I siti archeologici: un problema di musealizzazione all'aperto. Roma (1988).

[8] Camuffo, D. Microclimate for Cultural heritage. Conservation, Restoration and Manteinance of Indoor and Outdoor Monuments. San Diego, (2014). .

[9] Aslan, Z. Protective structures for the conservation and presentation of archaeological sites. Conservation and management of archaeological sites (2001) 5:73-85.

[10] Panosa, M.I. Musealizing Archaeological Sites. Considerations on Research, Conservation, and Dissemination: A Case Study from the Gavà Mines Archaeological Park. Conservation and Management of Archaeological Sites, 17:2, 159-174. (2015)

[11] Pedelì, C. and Pulga S. Pratiche conservative sullo scavo archeologico. Principi e metodi. Firenze, (2002).

[12] Laurenti, M.C., (Ed). La copertura di aree archeologiche. Museo Aperto. Roma, (2006).

[13] Michaelides, D. (Ed.) Mosaics make a site: the conservation in situ of mosaics in archaeological sites. Proceedings of the VI international conference of the International Committee for the Conservation of Mosaics (1996). ICCROM, (2003). 
[14] Roby, T. and Demas, M. (Eds.) Mosaics in situ. An overview of literature on conservation of mosaics in situ. Los Angeles, (2012).

[15] Palumbo, G. and Teutonico, J. M. (Eds.). Management planning for archaeological sites. Los Angelese, (2000).

[16] De La Torre, M., (Ed.). Conservation of Archaeological Sites in the Mediterranean Region. Los Angeles, (1997).

[17] Brandi, C. Teoria del Restauro. Torino, (1977).

[18] Henry Cleere (2010) Management Plans for Archaeological Sites: A World Heritage Template, Conservation and Management of Archaeological Sites, 12:1, 4-12, (2010).

[19] Ruggieri Tricoli, M. C. Musei sulle rovine. Architetture nel contesto archeologico. Milano, (2007).

[20] Vaudetti, M., Minucciani V. and Canepa, S. (Eds.). Mostrare l'archeologia. Per un manuale-atlante degli interventi di valorizzazione. Torino, (2013).

[21] D'Agostino, S. and A. Melucco Vaccaro A. Il rudere archeologico: un contributo alla conoscenza della sua vulnerabilità. In Biscontin G. e G. Driussi G. (Eds.) Dal sito archeologico all'archeologia del costruito. Conoscenza Progetto e Conservazione. Padova, (1996).

[22] Carandini, A. Storie dalla terra. Manuale di scavo archeologico. Torino, (2010).

[23] Minissi, F. Ipotesi di impiego di coperture metalliche a protezione di zone archeologiche. Restauro 81, (1985).

[24] Sposito, C. Esigenze e requisiti delle coperture. In Sposito A. (Ed.) Coprire l'antico. Palermo, (2004).

[25] Huisman, D. J. (Ed.) Degradation of archaeological remains. Den Haag, (2009).

[26] Bikai, P. M. e Bikai P. Caring for the Cultural Heritage: Shelter. In: ACOR (American Center for Oriental Research) Newsletter 9.1, (1997).

[27] Russo, S. Strutture in composito. Sperimentazione teoria e applicazioni. Milano, (2011).

[28] Bank, L.C. Composite for construction: structural design with FRP materials. Wiley \& Sons, (2006).

[29] Izzo, M. Exploring the possible role of parametric design in locationing the compositional problem: theory and practice of an evolving approach toward the urban design perspective. Milano, (2017).

[30] Tedeschi, A. AAD Algorithms-aided design: Parametric strategies using Grasshopper, (2014).

[31] Gerbo, E.J. and Salikis, E.P. Optimizing a trussed frame subject to wind using Rhino, Grasshopper, Karamba and Galapagos. In: R.M. Brasil and Pauletti, R.M.O. (Eds.): Shells Membranes and spatial structures: Footprints (2014).

[32] Vierlinger, R. Multi objective design interface. Master thesis, Wien (2018).

[33] Bangash, M.Y.H. and Bangash, T. Elements of spatial structures - Analysis and design. Telford, (2003).

[34] https://www.karamba3d.com/, last visited on February 15, 2020

[35] Clarke, J.L. (Ed.) Structural design of polymer composites. EUROCOMP design and handbook. EFN SPON, (1996). 